\title{
Toll/interleukin-1 Receptor Domain-Only Protein of Arabidopsis Thaliana AtTX14 2IR, Produced By Alternative Splicing, Can Induce Defense Responses
}

Jaebeom Lim

Chungnam National University School of Biosciences and Biotechnology: Chungnam National University College of Biological Sciences and Biotechnology

Jinouk Yeon

Chungnam National University School of Biosciences and Biotechnology: Chungnam National University College of Biological Sciences and Biotechnology

\section{Sang-Kee Song}

Chosun University

Hankuil Yi ( $D$ hankuil@gmail.com )

Chungnam National University School of Biosciences and Biotechnology: Chungnam National University College of Biological Sciences and Biotechnology https://orcid.org/0000-0002-9951-7856

\section{Research Article}

Keywords: Toll/interleukin-1 receptor, TIR, defense, disease resistance, alternative splicing

Posted Date: April 3rd, 2021

DOl: https://doi.org/10.21203/rs.3.rs-378145/v1

License: (c) (i) This work is licensed under a Creative Commons Attribution 4.0 International License. Read Full License 


\section{Abstract}

Toll/interleukin - 1 receptor (TIR) domains, which have $\mathrm{NAD}^{+}$cleavage activity, are used as signaling modules in NOD-like receptors for defense responses. It has been shown that TIR domains not only form homo- or heterodimers with TIR domain-containing proteins but also interact with various proteins. A previous study showed that overexpression of Arabidopsis thaliana (Arabidopsis) AtTX14, encoding an Nterminal TIR domain and a C-terminal domain with unknown function, resulted in dwarfism and constitutive defense signaling or autoimmunity. Transgenic Arabidopsis overexpressing AtTX14 displays enhanced defense responses and associated dwarf phenotypes at $28^{\circ} \mathrm{C}$ compared with those at $22^{\circ} \mathrm{C}$, which differs from other mutant or transgenic Arabidopsis with constitutive defense responses. We found that AtTX14 is alternatively spliced to encode three different proteins, and the TIR domain itself can induce autoimmunity and elevated defense responses to the bacterial pathogen Pseudomonas syringae pv. tomato. In addition, we revealed that the transcription of AtTX14 is regulated by a positive feedback mechanism. With transient overexpression of three AtTX14 protein forms in tobacco leaves, providing a heterologous system free from the positive feedback of AtTX14 in Arabidopsis, we demonstrated that expression of a splicing variant encoding the TIR domain-only protein is sufficient to activate defense signaling. A deeper understanding of interaction networks involving AtTX14 will broaden our knowledge on how plant defense signaling is regulated in response to pathogen infection and ambient temperature changes.

\section{Key Message}

Toll/interleukin-1 receptor domain-only protein naturally produced from Arabidopsis thaliana TX14 by alternative splicing is necessary and sufficient for the aggravation of defense responses at a higher temperature.

\section{Introduction}

Plants have developed a multilayered immune system to deploy defense mechanisms in response to pathogen attacks appropriately. Two major types of receptors are utilized for surveillance of invading pathogens: surface-localized pattern recognition receptors (PRRs) and intracellular nucleotide-binding (NB) oligomerization domain (NOD)-like receptors (NLRs) (Jones and Dangl 2006; Barragan and Weigel 2020). Pathogen-associated molecular patterns (PAMPs) or microbe-associated molecular patterns, such as flg22 and chitin oligomers, are recognized by PRRs, triggering an immune response referred to as PAMP-triggered immunity (PTI) (Macho and Zipfel 2014; Yoon et al. 2018). Damage-associated molecular patterns of host origin are also perceived by PRR-like cellular surface receptors that modulate defense responses (Albert et al. 2019). However, pathogens secreting effector proteins, encoded by Avirulence genes, can neutralize PTIs and compromise plant resistance (Jones and Dangl 2006). In this case, the successful resistance of hosts can be mounted by effector-triggered immunity using NLRs, which monitor modifications in proteins targeted by pathogen effectors. Once activated, NLRs induce robust defense responses, which are associated with transcriptional boosting and reprogramming of 
defense-related genes, hypersensitive responses (HR) causing localized cell death, and systemic acquired resistance (Balint-Kurti 2019; Cui et al. 2015; Fu and Dong 2013). Depending on the domains located at the N-terminus, two major classes are found among NLRs with C-terminal leucine-rich repeats (LRR): Toll/interleukin-1 (TIR)-NB-LRR (TNL) and coiled-coil (CC) -NB-LRR (Dangl and Jones 2001; Cui et al. 2015). N-terminal TIR or CC domains in NLRs are important for defense signal transduction, and NB domains in NLRs are used as molecular switches, which turn on NLR-mediated signaling when ATP is bound (Bentham et al. 2017). LRR domains in the NLR have been implicated in effector recognition and auto-inhibition.

Plant TIR domains are similar to those of animals in crystal structures. While both plant and animal TIR domains share the central five $\beta$-strands surrounded by five a-helices, plant TIR domains have additional aD3 helix insertions that are not present in their animal counterparts (Chan et al. 2010; Bernoux et al. 2011; Williams et al. 2014). It has been shown that HR, which is vital for resistance responses against pathogens in plants, is mediated by the formation of TIR homodimers or heterodimers depending on the TIR domains involved in the interaction (Bernoux et al. 2011; Williams et al. 2014). Dimerization of two TIR molecules requires the interaction of key amino acid residues located at the 'AE interface' made between $\mathrm{aA}$ and $\mathrm{aE}$ helices, as well as those at the 'DE interface' made between $\mathrm{aD}$ and $\mathrm{aE}$ helices (Hyun et al. 2016; Zhang et al. 2017a). Recently, it was reported that the TIR domains in SNC1 (suppressor of npr1-1, constitutive 1) and RBA1 (response to the bacterial type III effector protein HopBA1) have NAD ${ }^{+}$ cleavage activity, and a specific glutamic acid superimposed on the catalytic glutamate of MilB in the crystal structure plays an essential role in NAD ${ }^{+}$degradation (Horsefield et al. 2019; Wan et al. 2019). Mutations of amino acid residues in AE or DE interfaces disrupting TIR dimerization were found to compromise both the induction of HR and NAD ${ }^{+}$cleavage activity (Wan et al. 2019; Zhang et al. 2017a).

In plants, TIR domains are also found in various proteins whose domain compositions are different from those of classical TNL NLRs. For example, TIR domains are found in TIR-NB (TN) proteins without LRR domains and TIR-X (TX) proteins, which have a TIR domain and another domain (X) that is neither NB nor LRR (Meyers et al. 2002). In a model plant, Arabidopsis thaliana (Arabidopsis), a total of 145 genes encoding TIR domain-containing proteins were identified (Meyers et al. 2003): 83 TNLs, 5 TNLXs, 2 TNTNLs, 2 TTNLs, 21 TNs including one pseudogene, 30 TXs including 3 pseudogenes, and 2 XTNXs. It has been reported that overexpression of $T X$ or TIR alone, such as AtTX12 and AtRBA1, can also induce elevated defense responses or cell death (Nandety et al. 2013; Nishimura et al. 2017; Song 2016).

Alternative splicing (AS) can produce multiple transcripts from a single precursor messenger RNA (premRNA) (Nilsen and Graveley 2010). In plants, AS appears to occur in most multiexonic genes (Chamala et al. 2015). At least one AS event was identified in 50.2\% Arabidopsis multi-exonic genes, even when only four types of AS-intron retention, alternative acceptor site, exon skipping, and alternative donor site -were considered. Another study revealed that intron retention is most common among different splicing types and is found in approximately $40 \%$ of AS events, singly or combined (Zhang et al. 2017b). AS plays an important role in reprogramming defense-related genes, both qualitatively by expressing distinct splicing variants and quantitatively by modulating the ratio of splicing variants (Rigo et al. 2019). It is 
known that complete resistance to tobacco mosaic virus requires two alternative transcripts of the tobacco $N$ gene, encoding a full TNL protein and a truncated protein with TN, and only the first LRR (Dinesh-Kumar et al. 2000). In addition, removing Arabidopsis RPS4 (resistance to pseudomonas syringae 4) introns with in-frame stop codons, which can be included by intron retention, abolishes these functions (Zhang and Gassmann. 2003; Zhang and Gassmann. 2007). Only partial resistance was observed in transgenic plants expressing intron-deficient and truncated RPS4 transcripts.

AtTX14 (AT2G32140) in Arabidopsis encodes a TX-type protein. Kato et al. reported a dwarf phenotype in transgenic plants transformed with gAtTX14, the AtTX14 genomic region under the control of the constitutive cauliflower mosaic virus (CaMV) 35S promoter, differing from a previous study (Kato et al. 2014; Nandety et al. 2013). Dwarfism is often found in plants displaying constitutive defense responses or autoimmunity (Chakraborty et al. 2018). In gAtTX14, upregulation of defense-related genes, such as enhanced disease susceptibility 1, phytoalexin deficient 4, and salicylic acid (SA) induction deficient 2, were also observed (Kato et al. 2014). Although dwarf phenotypes in most autoimmune plants are usually alleviated at $28^{\circ} \mathrm{C}$ compared with those at $22^{\circ} \mathrm{C}$ (Zhu et al. 2010 and references therein), the dwarf phenotype in gAtTX14 plants was found to be aggravated at $28^{\circ} \mathrm{C}$. Two AS variants, including one encoding a truncated protein made of only the TIR domain, have been reported for AtTX14, but the biological implications of AtTX14 AS have not been determined (Kato et al. 2014).

In this study, we demonstrate that AtTX14 encodes three proteins with distinct domain compositions, as a result of intron retention-type AS: (1) a full-length TX protein with a truncated domain of unknown function (DUF) 641 in addition to the TIR domain encoded by a fully spliced transcript (AtTX14 Full), (2) a TIR-only protein encoded by a splicing variant with the 2 nd intron retained (AtTX14 2IR), and (3) a protein with a truncated TIR encoded by another splicing variant with the first intron retained (AtTX14 1IR). We found that AtTX14 Full and 2IR with intact TIR can form homo- and heterodimers with each other, but AtTX14 1IR cannot. Defense responses, including positive feedback of AtTX14, are induced by overexpression of AtTX14Full and 2IR in Arabidopsis, but not by AtTX14 1IR. Results obtained with tobacco, a heterologous plant system allowing an assessment of phenotypic effects in the absence of endogenous AtTX14 feedback regulation, confirmed that the TIR domain in AtTX14 2IR and Full is sufficient to induce defense responses in plants.

\section{Materials And Methods}

\section{Plant materials and growth conditions}

Arabidopsisthaliana (L.) Heynh. accession Columbia was used as the wild-type Arabidopsis plant (WT). For phenotypic observations and gene expression analyses, plants were grown in soil at 22 or $28^{\circ} \mathrm{C}$ under long-day conditions ( $16 \mathrm{~h}$ light and $8 \mathrm{~h}$ dark)-18-day old Arabidopsis at $22^{\circ} \mathrm{C}$ and 14 -day old Arabidopsis at $28{ }^{\circ} \mathrm{C}$. To determine the resistance of transgenic Arabidopsis against Pseudomonas syringae pv. tomato, plants were grown for 2 weeks on half-strength Murashige and Skoog solid media 
$\left(\mathrm{pH}\right.$ 5.7) at $22^{\circ} \mathrm{C}$ under long-day conditions. For tobacco infiltration, Nicotianabenthamiana plants were grown for 4 weeks at $22^{\circ} \mathrm{C}$ under long-day conditions.

\section{Genomic DNA and RNA isolation}

Genomic DNA was isolated using the urea lysis miniprep protocol as described by Yeon et al. (2019), and total RNA was prepared using Trizol reagent (Invitrogen, Carlsbad, CA, USA) according to the manufacturer's instructions.

\section{CDNA synthesis and PCR}

cDNA was synthesized using ReverTra Ace-- ${ }^{T M}$ (Toyobo Co., Ltd, Osaka, Japan), following the manufacturer's protocol. For cloning, genomic DNA and alternatively spliced cDNAs of AtTX14 were amplified using $n$ Pfu-forte DNA polymerase (Enzynomics Inc., Daejeon, Korea), as follows: initial denaturation at $94^{\circ} \mathrm{C}$ for $3 \mathrm{~min}, 35$ cycles of denaturation at $94^{\circ} \mathrm{C}$ for $30 \mathrm{~s}$, annealing at $58^{\circ} \mathrm{C}$ for $30 \mathrm{~s}$, extension at $72{ }^{\circ} \mathrm{C}$ for $2 \mathrm{~min}$, and a final extension at $72^{\circ} \mathrm{C}$ for $5 \mathrm{~min}$. Semi-quantitative reverse transcription (RT) polymerase chain reaction (PCR) was performed using AccuPower ${ }^{\circledR}$ PCR PreMix (Bioneer Corp., Deajeon, Korea), while quantitative RT-PCR was performed using iQ $^{\text {TM }} S$ SYBR $^{\circledR}$ Green Supermix (Bio-Rad Laboratories, Hercules, CA, USA). Information on all primers used is listed in Table S1 (de Oliveira et al. 2016; Zhu et al. 2014).

\section{Protein sequence analysis and structure prediction}

Based on the nucleotide sequences of AtTX14-spliced mRNAs, primary protein sequences were predicted and aligned with multiple sequence alignments using Clustal Omega and Jalview 2.11.0 (Goujon et al. 2010, Waterhouse et al. 2009). The secondary structure was predicted based on a 3D protein model of AtTX14 Full, generated using SWISS-MODEL based on the crystal structure of the RPS4 TIR domain (Protein Data Bank ID: 4C6R) (Waterhouse et al. 2018; Williams et al. 2014).

\section{Construction of plant overexpression vector}

PCR products and a pCAMBIA3300m vector were digested using BamHI and Pstl (Enzynomics Inc.) and purified using the EZ-Pure ${ }^{\text {TM }}$ PCR Purification Kit ver.2 (Enzynomics Inc.). The pCAMBIA3300m vector was generated from pCAMBIA3300 by adding (1) an extra CaMV 35S promoter and (2) multiple cloning sites made up of $\mathrm{BamHl}, \mathrm{Kpnl}, \mathrm{SaCl}, \mathrm{Xbal}$, and Pstl recognition sequences downstream of the additional CaMV 35S promoter. AtTX14 1/R transgenic plants were generated by cloning AtTX14 genomic DNA from the start codon to the in-frame stop codon in the first intron at the multiple cloning site. In the case of AtTX14 2IR and Full transgenic plants, coding sequences amplified from cDNA were used for cloning.

\section{Agrobacteriumtumefaciens (Agrobacterium) and plant transformation}

Plant overexpression vectors were introduced into Agrobacterium strain GV3101 by the freeze-thaw method (Holsters et al. 1978). Transgenic plants were generated by the floral dipping method of WT 
plants using transformed Agrobacterium (Clough and Bent 1998). T1 transformants and their selfpollinated progenies were selected based on their resistance to glufosinate-ammonium (BASTA ${ }^{\circledR}$; BASF, Ludwigshafen, Germany).

\section{Yeast two-hybrid $(\mathrm{Y} 2 \mathrm{H})$ analyses}

pGBKT7 and pGADT7 (Takara Bio., Inc., Shiga, Japan), containing GAL4 DNA binding domain (BD) and activation domains $(A D)$, respectively, were used as bait and prey cloning vectors to investigate proteinprotein interactions in the $\mathrm{Y} 2 \mathrm{H}$ system. pGBKT7 and pGADT7 with the genes of interest were cotransformed into yeast $\mathrm{AH} 109$ strain, following the manufacturer's protocol for Yeastmaker ${ }^{\mathrm{rM}}$ Yeast Transformation System 2 (Clontech Laboratories, Mount View, CA, USA). Transformants were grown at 30 ${ }^{\circ} \mathrm{C}$ for 4-5 days (d) on synthetic dropout (SD) without leucine and tryptophan (-LT) or without leucine, tryptophan, and histidine (-LTH).

\section{Western blotting of proteins expressed in yeast}

Yeast total proteins were extracted from cells grown in YPDA medium (10 g Bacto yeast extract, $20 \mathrm{~g}$ Bacto peptone, and $40 \mathrm{mg}$ adenine hemisulfate in $1 \mathrm{~L}$ water) at $30^{\circ} \mathrm{C}$ overnight $(\mathrm{O} / \mathrm{N})$, using Urea/SDS protein extraction buffer ( $40 \mathrm{mM}$ Tris- $\mathrm{HCl}$ [pH 6.8], $5 \%$ sodium dodecyl sulfate [SDS], $30 \%$ glycerol, $2 \% \beta$ mercaptoethanol, and $8 \mathrm{M}$ urea). The proteins were separated on a 10\% SDS-PAGE gel and transferred onto a polyvinylidene difluoride membrane (Merck Group, Darmstadt, Germany) with a transfer buffer (4.5 $\mathrm{g}$ Tris, $7.765 \mathrm{~g}$ glycine, $0.05 \mathrm{~g}$ SDS, $175 \mathrm{~mL}$ methanol in $1 \mathrm{~L}$ water) at $100 \mathrm{~V}$ for 2 hours (h). After rinsing with water, the membranes were blocked using General-Block Solution (TransLab, Daejeon, Korea) for $1 \mathrm{~h}$. Membranes were washed once with PBS-T buffer $\left(8 \mathrm{~g} \mathrm{NaCl}, 0.2 \mathrm{~g} \mathrm{KCl}, 1.44 \mathrm{~g} \mathrm{Na}_{2} \mathrm{HPO}_{4}, 0.24 \mathrm{~g} \mathrm{KH}_{2} \mathrm{PO}_{4}, 2\right.$ $\mathrm{mL}$ Tween-20 in $1 \mathrm{~L}$ water) and incubated in PBS-T with the primary antibody, HA or Myc (Clontech Laboratories), at $4{ }^{\circ} \mathrm{C} 0 / \mathrm{N}$. After washing for $1 \mathrm{~h}$ with PBS-T, the membranes were incubated with horseradish peroxidase (HRP)-conjugated secondary antibody (Santa Cruz Biotechnologies Inc., Dallas, TX, USA) in PBS-T for $1 \mathrm{~h}$. HRP activity was detected using SuperSignal ${ }^{\circledR}$ West Pico Chemiluminescent Substrate (Thermo Fisher Scientific, Waltham, MA, USA) and ChemiDoc ${ }^{\mathrm{TM}}$ Touch Gel Imaging System (BioRad Laboratories).

\section{Infection of Arabidopsis with P. syringae pv. tomato}

DC3000 and DC3000 (AvrRpm1), P. syringae without or with the AvrRpm1 effector protein, were infected into 2-week-old Arabidopsis, and colony-forming units (CFUs) were determined at 0 and $3 \mathrm{~d}$ post infiltration (dpi), as described by Ishiga et al. (2017). In brief, plants were inoculated by flooding with a bacterial suspension $\left(4 \times 10^{6} \mathrm{CFU} \mathrm{mL}^{-1}\right.$ in $0.025 \% \mathrm{v} / \mathrm{v}$ Silwet L-77 and $10 \mathrm{mM} \mathrm{MgCl}_{2}$ ).

\section{Transient protein expression in tobacco by agroinfiltration and measurement of chlorophyll contents}

Agroinfiltration was performed using a previously described method, with slight modifications (Kim et al. 2018; Kontra et al. 2016). In brief, seed cultures of Agrobacterium GV3101 carrying an overexpression 
vector for the corresponding AtTX14 AS variant and $p 19$, an RNA silencing suppressor, were grown in LB medium containing appropriate antibiotics at $25^{\circ} \mathrm{C}$ for $2 \mathrm{~d}$. The main cultures were grown at $25^{\circ} \mathrm{C} \mathrm{O} / \mathrm{N}$ after seed culture inoculation. Harvested cells were resuspended in infiltration buffer (10 mM MES [pH 5.7], $10 \mathrm{mM} \mathrm{MgCl}_{2}$, and $200 \mu \mathrm{M}$ acetosyringone) and diluted to an $\mathrm{OD}_{600}$ of 1.0. After a 2-h incubation, Agrobacteria to be tested in combinations were mixed and infiltrated together onto the lower sides of 4week-old tobacco leaves. The induction of HR was assessed $10 \mathrm{~d}$ after agroinfiltration. Chlorophyll content in tobacco leaf segments was measured $10 \mathrm{~d}$ after Agrobacterium infiltration, as described by Harris et al. (2013).

\section{Results}

\section{AtTX14 transcripts produced by distinct intron retentions encode three AtTX14 proteins}

A previous study reported that $A t T X 14$ has an alternatively spliced form generated by the retention of the second intron and encodes a protein with a TIR domain (Fig. S1) and a short C-terminal extension (Kato et al. 2014). It was found that the first intron of AtTX14 could also be retained, yet another alternatively spliced mRNA transcript was produced (Fig. 1A). The presence of an mRNA transcript containing the first intron of $A t T X 14$ is supported by the Reference Transcript Dataset for Arabidopsis, in which three differently processed mRNAs of AtTX14-Spliced mRNA 1, 2, and 3 have been reported (Zhang et al. 2017b) (Fig. 1B). Spliced mRNA 1, containing the first intron but lacking the second intron, encodes a protein with 185 amino acids (aa) made of a truncated TIR domain (aa 21-166) and 19-aa C-terminal extension produced from the first intron sequence. In contrast, Spliced mRNA 2, in which the first intron is spliced out, but the second intron is retained, encodes a 220 aa-long protein with an intact TIR domain (aa 21-188) and 32-aa C-terminal extension, as previously reported (Kato et al. 2014). Spliced mRNA 3 without intron sequences encodes a 353 aa-long protein made of an intact TIR domain (aa 21-188) and 165 aa-long C-terminal extension. We named the translational products of Spliced mRNA 1, 2, and 3 as AtTX14 1IR (first intron retention form), AtTX14 2IR (second intron retention form), and AtTX14 Full (fulllength form), respectively (Fig. 1B).

Sequence alignment of the C-terminal part of AtTX14 Full and related proteins, a transcriptional regulator CHIQ1 and ten CHIQLs, revealed that the C-terminal half of AtTX14 Full contains a truncated DUF641 domain (Bossi et al. 2017) (Fig. S2). CHIQL7 (AT2G32130), located downstream of AtTX14 and transcribed in the same direction as AtTX14, was predicted to encode a protein with an intact DUF641 domain. Our results show that the upregulation of AtTX14, which activates defense signaling, produces three different proteins with truncated TIR, intact TIR only, and intact TIR plus a truncated DUF641.

\section{AtTX14 2IR and AtTX14 Full can form homo- and heterodimers}

Modeling of the AtTX14 Full structure based on the crystal structure of the RPS4 TIR domain (Protein Data Bank ID: 4C6R) using SWISS-MODEL revealed that AtTX14 1IR has an incomplete TIR domain with a modified aE helix and a loop leading to the aE helix (EE loop), compared with the TIR domains in 
AtTX14 Full and AtTX14 2IR (Fig. 2) (Waterhouse et al. 2018; Williams et al. 2013). Because the EE loop and $\mathrm{aE}$ helix are important for protein-protein interaction of TIR domains (Hyun et al. 2016; Zhang et al. 2017a), we tested whether the three proteins translated from AtTX14-spliced mRNAs can form homo- or heterodimers using the $\mathrm{Y} 2 \mathrm{H}$ system. In the $\mathrm{Y} 2 \mathrm{H}$ analyses, AtTX14 2IR or Full was found to form a homodimer when fused to GAL4 BD and AD, allowing the growth of co-transformed yeasts on selective media (Fig. 3). Furthermore, AtTX14 2IR and Full were found to form a heterodimer. In contrast to the other forms, AtTX14 1IR with a modified aE helix and an EE loop could not form a homodimer, and heterodimers with AtTX14 2IR or Full, although AtTX14 1IR fused to BD or AD is expressed as expected in yeast cells (Fig. S3). The EE loop and aE helix present in AtTX14 are important for TIR dimer formation (Hyun et al. 2016, Williams et al. 2014, Zhang et al. 2017a).

\section{Transgenic overexpression of the AtTX14 TIR domain induces dwarfism}

Regarding plant phenotypes induced by the transgenic overexpression of AtTX14, inconsistent observations have been reported by two groups: one reported dwarfism, but the other reported no phenotypic change (Kato et al. 2014; Nandety et al. 2013). To resolve this discrepancy, we generated transgenic plants, gAtTX14, in which $1.3 \mathrm{~kb}$ genomic DNA covering from the start to the stop codon of AtTX14 is regulated by the constitutive CaMV 35S promoter, and investigated the phenotypes. In line with the Kato group's observation but different from that of the Meyers group, we found that upregulation of AtTX14 induces stunted growth leading to dwarfism (Fig. 4A). To unequivocally determine whether the expression of one specific spliced form of AtTX14 or a combination of AtTX14 spliced forms is necessary for dwarfism, we generated transgenic plants, in which AtTX14 1IR, 2IR, or Full was specifically overexpressed by transgenes. Morphological observation of AtTX14 1IR, 2IR, or Full transgenic plants revealed that dwarfism was induced by transgenic expression of AtTX14 2IR or Full, but not by overexpression of AtTX14 1IR (Fig. 4A).

\section{AtTX14 is regulated by a positive feedback mechanism to induce defense responses}

Some $N L R$ genes are regulated by a positive feedback mechanism that requires accumulation of $\mathrm{SA}$, a plant hormone playing important roles in plant disease resistance (Delaney et al. 1994; Xiao et al. 2003). Expression analyses showed that AtTX14 is upregulated by biotic stress conditions, such as pathogen infection and elicitor treatment, resulting in SA accumulation (Nandety et al. 2013), raising the possibility that the amplification circuit also regulates AtTX14 transcription through SA accumulation. When the expression levels of AtTX14 were compared between WT and ba/variants, in which constitutive defense responses caused by the duplication of $S N C 1$ are regulated by the SA-mediated positive feedback mechanism (Yi and Richards 2007, 2009), a stronger expression of AtTX14 was observed in the bal variant (Fig. S4A). Moreover, SNC1 expression was found to be elevated in AtTX14Full transgenic plants (Fig. S4B). To address the question of whether AtTX14 is controlled by a positive feedback mechanism, we determined the expression levels of endogenous AtTX14 using primers that differentiate endogenous and transgenic AtTX14 transcripts (Fig. S5). Expression levels of alternatively spliced forms with or without introns originating from the endogenous AtTX14 gene were increased in AtTX14 2IR and Full 
transgenic plants showing dwarfism (Fig. 4B), whereas feedback induction of endogenous AtTX14 transcription was not observed in AtTX14 1IR transgenic plants.

The expression of Pathogenesis related 1 (PR1), a marker for SA-dependent defense responses (Uknes et al. 1992; Delaney et al. 1994), was found to be elevated in AtTX14 2IR and Full transgenic plants, compared with WT plants (Fig. 5A). In general, stronger induction of PR1 was observed in AtTX14 Full transgenic plants than in AtTX14 2IR plants (Fig. 5B), when expression levels of $P R 1$ were normalized to those of the transgenes expressed in Fig. 4B. We also tested whether overexpression of the TIR domain in AtTX14 2IR increases the resistance of transgenic plants to the bacterial pathogen, $P$. syringae pv. tomato (Pst). While no significant difference in the growth of Pst was observed between WT plants and AtTX14 $1 / R$ plants at $3 \mathrm{~d}$ post-infection (dpi), the growth of the bacteria was suppressed in the AtTX14 2IR plants compared with that in WT plants at 3 dpi (Fig. 5C). AtTX14 2IR plants were found to be more resistant to both virulent $P s t$, DC3000 without the AvrRpm1 effector, and avirulent Pst, DC3000 (AvrRpm1) with AvrRpm1 effector.

\section{Elevated temperature enhances dwarfism in AtTX14 2IR transgenic plants}

For gAtTX14 transgenic plants, a more dramatic decrease in the length and width of the largest leaves, as well as more severe inhibition of stem elongation, was observed in growth at $28{ }^{\circ} \mathrm{C}$ than at $22^{\circ} \mathrm{C}$ (Kato et al. 2014). Because multiple splicing variants were detected with slightly different ratios in the gAtTX14 transgenic plants at different temperatures, it was unclear whether a specific splicing variant could induce high temperature-dependent phenotypic enhancement. We found that stunting phenotypes in AtTX14 2IR plants, which overexpress the AtTX14 TIR domain without the C-terminal-truncated DUF641 domain, were more severe at 28 than at $22^{\circ} \mathrm{C}$ (Fig. 6A). $2 / R$ transgenic plants grown for $14 \mathrm{~d}$ at $28^{\circ} \mathrm{C}$ had less than $20 \%$ fresh weight compared with $2 I R$ transgenic plants grown for $18 \mathrm{~d}$ at $22^{\circ} \mathrm{C}$ (Fig. $6 \mathrm{~B}$ ). In contrast, WT plants grown for $14 \mathrm{~d}$ at $28^{\circ} \mathrm{C}$ had about $50 \%$ fresh weight compared with WT plants grown at $22^{\circ} \mathrm{C}$.

\section{Expression of AtTX14 2IR or AtTX14Full itself is sufficient to induce defense responses}

Since transgenic expression of either AtTX14 2IR or AtTX14 Full can activate the transcription of all possible spliced variants from endogenous AtTX14 via a positive feedback mechanism in Arabidopsis (Fig. 4B), it was unclear whether defense-associated phenotypic and gene expression changes observed in these transgenic plants are direct outcomes of the corresponding transgene expression. It is also possible that one or a combination of transcriptionally induced endogenous AtTX14-spliced mRNA(s) indirectly contributes to the defense responses. To test whether a specific AtTX14 splicing variant can induce defense responses in the absence of the positive feedback mechanism in Arabidopsis, we took advantage of the Agrobacterium-mediated transient expression system using tobacco leaves, which are not interfered with by the feedback-regulated AtTX14 in Arabidopsis. Overexpression of AtTX14 2IR or Full with p19 RNA silencing suppressor in tobacco leaves induced HR-like chlorosis (Fig. 7A), but no phenotypic differences were observed in leaf parts where $p 19$ and AtTX14 1IR were expressed together. Consistently, AtTX14 2IR and Full-infiltrated leaf areas were found to have lower amounts of chlorophyll 
than AtTX14 1IR-infiltrated leaf areas (Fig. 7B). Because both AtTX14 2IR and Full protein carry an intact AtTX14 TIR domain and transient expression of 2IR is sufficient to induce HR and decrease chlorophyll content in the heterologous tobacco system, we concluded that expression of the AtTX14 TIR domain itself is sufficient to activate defense responses.

\section{Discussion}

The TIR domain-only protein of AtTX14, which is naturally produced by AS, is sufficient to induce defense responses (Fig. 5 and 7). The observation that $P R 1$ expression is elevated without pathogen infection in AtTX14 2IR transgenic plants and AtTX14 2IR plants are more resistant to Pst bacterial pathogens, regardless of avirulence gene presence, indicates that overexpression of the TIR domain in AtTX14 causes constitutive defense signaling. The AtTX14 second intron, if retained in the Spliced mRNA 2, introduces an in-frame stop codon, making AtTX14 2IR have an intact TIR domain but lack the 133-aa AtTX14 Full C-terminal region (Fig. 1B). In addition to TIR domain-containing proteins, such as TNL, TN, or TX (Kato et al. 2014; Nandety et al. 2013; Nishimura et al. 2017; Roth et al. 2017; Santamaría et al. 2019), some TIR domains alone have been shown to induce HR in plants when overexpressed after removing other domains such as NB and/or LRR (Bernoux et al. 2011; Swiderski et al. 2009). Based on the finding that $R B A 1$ in the Ag-0 accession, which was previously thought to be TX but found to encode TIR-only protein, is sufficient to induce defense responses (Nishimura et al. 2017), as well as AtTX14 2IR, we speculate that more TIR-only proteins, which play important roles in defense signaling, can be identified by re-annotation and close investigation of AS patterns of TIR domain-encoding genes. In addition, some Arabidopsis genes that were originally classified as $T X$ need to be reclassified as $T I R$ genes. AtTX12 (AT2G03300) encodes a 203 aa-long protein classified as TX, which results in the activation of defense signaling and growth defects (Song, 2016). The relatively short C-terminal extension (aa 165-204) in AtTX12 does not show any sequence similarity to known protein domains in the conserved domain database (https://www.ncbi.nlm.nih.gov/cdd) and is, therefore, more appropriate for classification as a TIR-only protein.

Given that AtTX14 2IR is not only capable of initiating a positive feedback loop (Fig. 4B) but also induces an HR-like phenotype by itself in tobacco (Fig. 7A), we conclude that the C-terminal region (aa 221-353) of AtTX14 Full with the truncated DUF641 domain is dispensable for the activation of defense responses. However, comparable levels of dwarf phenotypes and transcription of endogenous AtTX14 were observed between AtTX14 Full and 2IR transgenic plants in our experiments, when significantly smaller amounts of transgene transcripts were expressed in AtTX14 Full than in AtTX14 2IR (Fig. 4B). Although the C-terminal non-TIR part of AtTX14 Full, the truncated DUF641, is not necessary to induce dwarfism and HR, we do not rule out the possibility that the C-terminal part may increase the stability or activity of the AtTX14 TIR domain. Possible differences in protein translational efficiency and/or stability between AtTX14 2IR and Full requires further investigation. With the finding that both AtTX14 2IR and Full with intact TIR are positive components in plant defense signaling (Fig. 5-7), it needs to be determined which proteins can interact with AtTX14 proteins with intact TIR and how defense responses are activated by AtTX14 Full or 2IR expression. It also needs to be determined whether AtTX14 proteins, including AtTX14 1IR with the 
critical glutamate residue for catalytic activity, have NADase activity (Horsefield et al. 2019; Wan et al. 2019).

\section{Declarations}

\section{Acknowledgment}

This work was supported by a grant (NRF-2017R1D1A3B04035080) from the Ministry of Education in the Republic of Korea through the Basic Science Research Program of the National Research Foundation of Korea and ICT (No. 2020-0-01441, Artificial Intelligence Convergence Research Center at Chungnam National University), Republic of Korea.

\section{Funding}

This work was supported by a grant (NRF-2017R1D1A3B04035080) from the Ministry of Education in the Republic of Korea through the Basic Science Research Program of the National Research Foundation of Korea and ICT (No. 2020-0-01441, Artificial Intelligence Convergence Research Center at Chungnam National University), Republic of Korea.

\section{Conflicts of interest/Competing interests}

Not Applicable

\section{Availability of data and material}

Please contact the corresponding author, Hankuil Yi.

\section{Code availability}

Not Applicable

\section{Authors' contributions}

JL, SS and HY designed experiments and wrote manuscript. JL and JY conducted experiments.

\section{References}

1. Albert I, Hua C, Nürnberger T, et al (2020) Surface sensor systems in plant immunity. Plant Physiol 182:1582-1596. https://doi.org/10.1104/PP.19.01299

2. Balint-Kurti P (2019) The plant hypersensitive response: concepts, control and consequences. Mol Plant Pathol 20:1163-1178. https://doi.org/10.1111/mpp.12821

3. Barragan AC, Weigel D (2020) Plant NLR Diversity: The Known Unknowns of Pan-NLRomes A Brief History of Plant NLRs. Plant Cell koaa002. https://doi.org/10.1093/plcell/koaa002 
4. Bentham A, Burdett $H$, Anderson PA, et al (2017) Animal NLRs provide structural insights into plant NLR function. Ann Bot 119:689-702. https://doi.org/10.1093/aob/mcw171

5. Bernoux M, Ve T, Williams S, et al (2011) TIR Domain Reveals Interfaces for Self-Association, Signaling, and Autoregulation. Cell Host Microbe 9:200-211. https://doi.org/10.1016/j.chom.2011.02.009.Bernoux

6. Bossi F, Fan J, Xiao J, et al (2017) Systematic discovery of novel eukaryotic transcriptional regulators using sequence homology independent prediction. BMC Genomics 18:1-20. https://doi.org/10.1186/s12864-017-3853-9

7. Chakraborty J, Ghosh P, Das S (2018) Autoimmunity in plants. Planta 248:751-767. https://doi.org/10.1007/s00425-018-2956-0

8. Chamala S, Feng G, Chavarro C, Barbazuk WB (2015) Genome-wide identification of evolutionarily conserved alternative splicing events in flowering plants. Front Bioeng Biotechnol 3:33. https://doi.org/10.3389/fbioe.2015.00033

9. Chan SL, Mukasa T, Santelli E, et al (2010) The crystal structure of a TIR domain from Arabidopsis thaliana reveals a conserved helical region unique to plants. Protein Sci 19:155-161. https://doi.org/10.1002/pro.275

10. Clough SJ, Bent AF (1998) Floral dip: A simplified method for Agrobacterium-mediated transformation of Arabidopsis thaliana. Plant J 16:735-743. https://doi.org/10.1046/j.1365313X.1998.00343.x

11. Cui H, Tsuda K, Parker JE (2015) Effector-triggered immunity: From pathogen perception to robust defense. Annu Rev Plant Biol 66:487-511. https://doi.org/10.1146/annurev-arplant-050213-040012

12. Dangl JL, Jones JDG (2001) Plant pathogens and integrated defence responses to infection. Nature 411:826-833. https://doi.org/10.1038/35081161

13. De Oliveira MVV, Xu G, Li B, et al (2016) Specific control of Arabidopsis BAK1/SERK4-regulated cell death by protein glycosylation. Nat Plants 2:15218. https://doi.org/10.1038/nplants.2015.218

14. Delaney TP, Uknes S, Vernooij B, et al (1994) A central role of salicylic acid in plant disease resistance. Science 266:1247-1250. https://doi.org/10.1126/science.266.5188.1247

15. Dinesh-Kumar SP, Baker BJ (2000) Alternatively spliced N resistance gene transcripts: Their possible role in tobacco mosaic virus resistance. Proc Natl Acad Sci U S A 97:1908-1913. https://doi.org/10.1073/pnas.020367497

16. Fu ZQ, Dong X (2013) Systemic acquired resistance: Turning local infection into global defense. Annu Rev Plant Biol 64:839-863. https://doi.org/10.1146/annurev-arplant-042811-105606

17. Goujon M, McWilliam H, Li W, et al (2010) A new bioinformatics analysis tools framework at EMBLEBI. Nucleic Acids Res 38:695-699. https://doi.org/10.1093/nar/gkq313

18. Harris CJ, Slootweg EJ, Goverse A, Baulcombe DC (2013) Stepwise artificial evolution of a plant disease resistance gene. Proc Natl Acad Sci U S A 110:21189-21194.

https://doi.org/10.1073/pnas.1311134110

Page 12/23 
19. Holsters M, de Waele D, Depicker A, et al (1978) Transfection and transformation of Agrobacterium tumefaciens. MGG Mol Gen Genet 163:181-187. https://doi.org/10.1007/BF00267408

20. Horsefield S, Burdett $H$, Zhang $X$, et al (2019) NAD+ cleavage activity by animal and plant TIR domains in cell death pathways. Science 365:793-799. https://doi.org/10.1126/science.aax1911

21. Hyun K gi, Lee Y, Yoon J, et al (2016) Crystal structure of Arabidopsis thaliana SNC1 TIR domain. Biochem Biophys Res Commun 481:146-152. https://doi.org/10.1016/j.bbrc.2016.11.004

22. Ishiga Y, Ishiga T, Uppalapati SR, Mysore KS (2011) Arabidopsis seedling flood-inoculation technique: A rapid and reliable assay for studying plant-bacterial interactions. Plant Methods 7:32. https://doi.org/10.1186/1746-4811-7-32

23. Jeong SW, Yi H, Song H, et al (2017) Chlorosis of Ogura-CMS Brassica rapa is due to downregulation of genes for chloroplast proteins. J Plant Biotechnol 44:115-124. https://doi.org/10.5010/JPB.2017.44.2.115

24. Jones JDG, Dangl JL (2006) The plant immune system. Nature 444:323-329. https://doi.org/10.1038/nature05286

25. Kato H, Saito T, Ito H, et al (2014) Overexpression of the TIR-X gene results in a dwarf phenotype and activation of defense-related gene expression in Arabidopsis thaliana. J Plant Physiol 171:382-388. https://doi.org/10.1016/j.jplph.2013.12.002

26. Kim EJ, Lee SH, Park CH, Kim TW (2018) Functional Role of BSL1 Subcellular Localization in Brassinosteroid Signaling. J Plant Biol 61:40-49. https://doi.org/10.1007/s12374-017-0363-x

27. Kontra L, Csorba T, Tavazza M, et al (2016) Distinct Effects of p19 RNA Silencing Suppressor on Small RNA Mediated Pathways in Plants. PLoS Pathog 12:1-26. https://doi.org/10.1371/journal.ppat.1005935

28. Kunkel BN, Brooks DM (2002) Cross talk between signaling pathways in pathogen defense. Curr Opin Plant Biol 5:325-331. https://doi.org/10.1016/S1369-5266(02)00275-3

29. Li Y, Yang S, Yang H, Hua J (2007) The TIR-NB-LRR gene SNC1 is regulated at the transcript level by multiple factors. Mol Plant-Microbe Interact 20:1449-1456. https://doi.org/10.1094/MPMI-20-111449

30. Macho AP, Zipfel C (2014) Plant PRRs and the activation of innate immune signaling. Mol Cell 54:263-272. https://doi.org/10.1016/j.molcel.2014.03.028

31. Manners JM, Penninckx IAMA, Vermaere K, et al (1998) The promoter of the plant defensin gene PDF1.2 from Arabidopsis is systemically activated by fungal pathogens and responds to methyl jasmonate but not to salicylic acid. Plant Mol Biol 38:1071-1080. https://doi.org/10.1023/A:1006070413843

32. Meyers BC, Kozik A, Griego A, et al (2003) Genome-wide analysis of NBS-LRR-encoding genes in Arabidopsis. Plant Cell 15:809-834. https://doi.org/10.1105/tpc.009308

33. Meyers BC, Morgante M, Michelmore RW (2002) TIR-X and TIR-NBS proteins: Two new families related to disease resistance TIR-NBS-LRR proteins encoded in Arabidopsis and other plant genomes. Plant J 32:77-92. https://doi.org/10.1046/j.1365-313X.2002.01404.x 
34. Nandety RS, Caplan JL, Cavanaugh K, et al (2013) The role of TIR-NBS and TIR-X proteins in plant basal defense responses. Plant Physiol 162:1459-1472. https://doi.org/10.1104/pp.113.219162

35. Nilsen TW, Graveley BR (2010) Expansion of the eukaryotic proteome by alternative splicing. Nature 463:457-463. https://doi.org/10.1038/nature08909

36. Nishimura MT, Anderson RG, Cherkis KA, et al (2017) TIR-only protein RBA1 recognizes a pathogen effector to regulate cell death in Arabidopsis. Proc Natl Acad Sci U S A 114:E2053-E2062. https://doi.org/10.1073/pnas.1620973114

37. Rigo R, Bazin J, Crespi M, Charon C (2019) Alternative Splicing in the Regulation of Plant-Microbe Interactions. Plant Cell Physiol 60:1906-1916. https://doi.org/10.1093/pcp/pcz086

38. Roth C, Lüdke D, Klenke M, et al (2017) The truncated NLR protein TIR-NBS13 is a MOS6/IMPORTINa3 interaction partner required for plant immunity. Plant J 92:808-821. https://doi.org/10.1111/tpj.13717

39. Santamaría ME, Martínez M, Arnaiz A, et al (2019) An arabidopsis TIR-lectin two-domain protein confers defense properties against tetranychus urticae. Plant Physiol 179:1298-1314. https://doi.org/10.1104/pp.18.00951

40. Song SK (2016) Misexpression of AtTX12 encoding a Toll/interleukin-1 receptor domain induces growth defects and expression of defense-related genes partially independently of EDS1 in Arabidopsis. BMB Rep 49:693-698. https://doi.org/10.5483/BMBRep.2016.49.12.180

41. Swiderski MR, Birker D, Jones JDG (2009) The TIR domain of TIR-NB-LRR resistance proteins is a signaling domain involved in cell death induction. Mol Plant-Microbe Interact 22:157-165. https://doi.org/10.1094/MPMI-22-2-0157

42. Uknes S, Mauch-Mani B, Moyer M, et al (1992) Acquired resistance in arabidopsis. Plant Cell 4:645656. https://doi.org/10.1105/tpc.4.6.645

43. Wan L, Essuman K, Anderson RG, et al (2019) TIR domains of plant immune receptors are NAD+cleaving enzymes that promote cell death. Science (80- ) 365:799-803. https://doi.org/10.1126/science.aax1771

44. Waterhouse AM, Procter JB, Martin DMA, et al (2009) Jalview Version 2-A multiple sequence alignment editor and analysis workbench. Bioinformatics 25:1189-1191. https://doi.org/10.1093/bioinformatics/btp033

45. Waterhouse A, Bertoni M, Bienert S, et al (2018) SWISS-MODEL: Homology modelling of protein structures and complexes. Nucleic Acids Res 46:W296-W303. https://doi.org/10.1093/nar/gky427

46. Wildermuth MC, Dewdney J, Wu G, Ausubel FM (2002) Erratum: Isochorismate synthase is required to synthesize salicylic acid for plant defence (Nature (2001) 414 (562-565)). Nature 417:571. https://doi.org/10.1038/417571a

47. Williams SJ, Sohn KH, Wan L, et al (2014) Structural Basis for Assembly and Function of a Heterodimeric Plant Immune Receptor. Science (80- ) 344:299-303. https://doi.org/10.1126/science. 1247357 
48. Xiao S, Brown S, Patrick E, et al (2003) Enhanced Transcription of the Arabidopsis Disease Resistance Genes. Society 15:33-45. https://doi.org/10.1105/tpc.006940.2001

49. Yeon J, Park JS, Lee SH, et al (2019) Overexpression of Cuphea viscosissima CvFatB4 enhances 16:0 fatty acid accumulation in Arabidopsis. J Plant Biotechnol 46:282-290. https://doi.org/10.5010/JPB.2019.46.4.282

50. Yi H, Richards EJ (2009) Gene duplication and hypermutation of the pathogen Resistance gene SNC1 in the arabidopsis bal variant. Genetics 183:1227-1234. https://doi.org/10.1534/genetics.109.105569

51. Yi H, Richards EJ (2007) A cluster of disease resistance genes in Arabidopsis is coordinately regulated by transcriptional activation and RNA silencing. Plant Cell 19:2929-2939. https://doi.org/10.1105/tpc. 107.051821

52. Yun HS, Lee JH, Park WJ, Kwon C (2018) Plant Surface Receptors Recognizing Microbe-Associated Molecular Patterns. J Plant Biol 61:111-120. https://doi.org/10.1007/s12374-018-0075-X

53. Zhang R, Calixto CPG, Marquez Y, et al (2017) A high quality Arabidopsis transcriptome for accurate transcript-level analysis of alternative splicing. Nucleic Acids Res 45:5061-5073. https://doi.org/10.1093/nar/gkx267

54. Zhang X, Bernoux M, Bentham AR, et al (2017) Multiple functional self-association interfaces in plant TIR domains. Proc Natl Acad Sci U S A 114:E2046-E2052.

https://doi.org/10.1073/pnas.1621248114

55. Zhang XC, Gassmann W (2007) Alternative splicing and mRNA levels of the disease resistance gene RPS4 are induced during defense responses. Plant Physiol 145:1577-1587. https://doi.org/10.1104/pp.107.108720

56. Zhang XC, Gassmann W (2003) RPS4-Mediated Disease Resistance Requires the Combined Presence of RPS4 Transcripts with Full-Length and Truncated Open Reading Frames. Plant Cell 15:2333-2342. https://doi.org/10.1105/tpc.013474

57. Zhang Y, Goritschnig S, Dong X, Li X (2003) A Gain-of-Function Mutation in a Plant Disease Resistance Gene Leads to Constitutive Activation of Downstream Signal Transduction Pathways in suppressor of npr1-1, constitutive 1. Plant Cell 15:2636-2646. https://doi.org/10.1105/tpc.015842

58. Zhu Y, Schluttenhoffer CM, Wang P, et al (2014) CYCLIN-DEPENDENT KINASE8 differentially regulates plant immunity to fungal pathogens through kinase-dependent and -independent functions in Arabidopsis. Plant Cell 26:4149-4170. https://doi.org/10.1105/tpc.114.128611

\section{Figures}


a

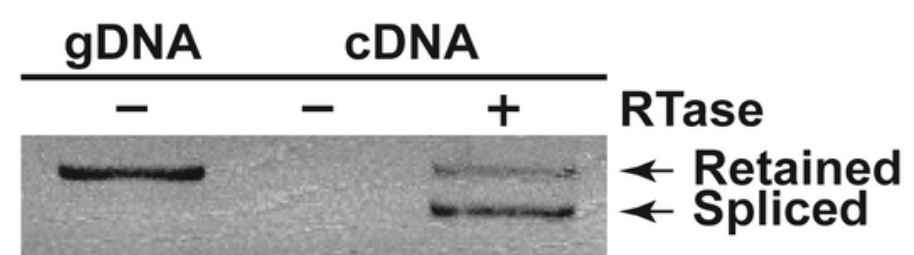

b

pre-mRNA

\begin{tabular}{|l|l|}
\hline $5 \mathrm{U}$ & $\mathrm{I}$ \\
\hline
\end{tabular}

\section{Spliced mRNA 1}

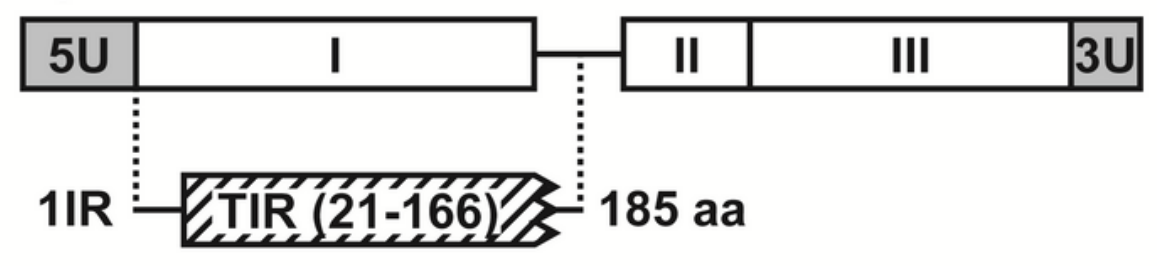

\section{Spliced mRNA 2}

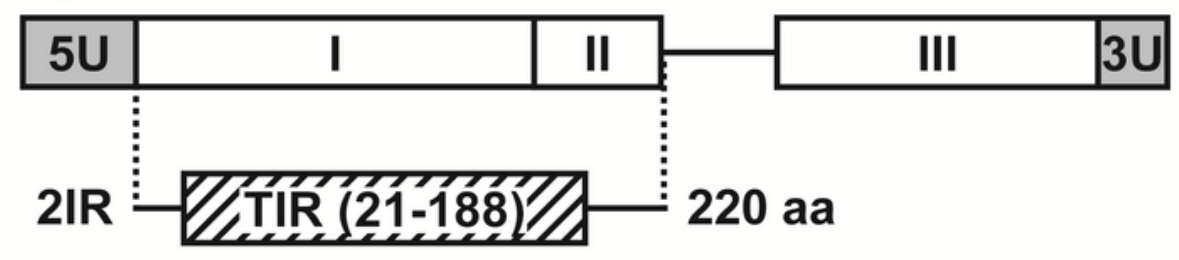

\section{Spliced mRNA 3}

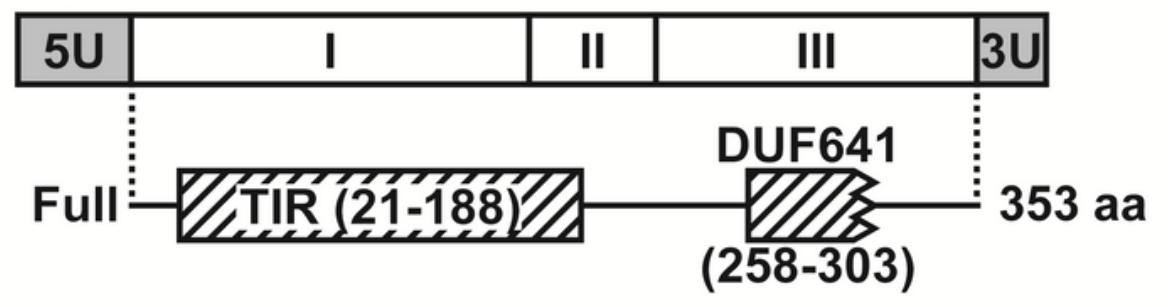

\section{Figure 1}

AtTX14 encodes three different protein forms by AS. (A) Agarose gel electrophoresis results of PCR products amplified with WT genomic DNA template and cDNA templates synthesized in the absence (-) or presence of $(+)$ reverse transcriptase (RTase). Retained and Spliced indicate PCR products with or without the first intron of AtTX14. (B) Three different proteins (1IR, 2IR, and Full) encoded by alternatively spliced AtTX14 of introns (Spliced mRNA 1, 2, and 3). Exons and UTRs are represented by boxes, while the 
introns are indicated by lines. White and gray boxes indicate exons $(\nabla, \nabla$, and $\nabla)$ and 5 ' or $3^{\prime}$ untranslated regions ( $5 \mathrm{U}$ or $3 \mathrm{U})$, respectively, while lines indicate introns. Hatched boxes represent conserved domains in the AtTX14 proteins, with the names and amino acid positions in the parentheses. The truncations of domains are shown by zigzagged lines. Protein lengths are indicated on the right.

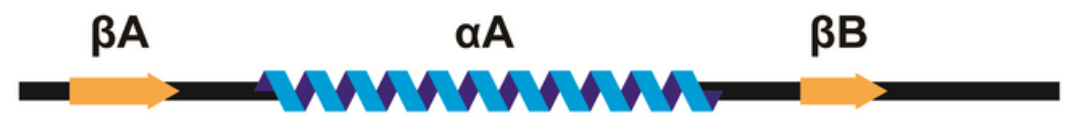

AtTX14 Full AtTX14 2IR AtTX14 1IR

AtTX14 Full AtTX14 2IR AtTX14 1IR

AtTX14 Full AtTX14 2IR AtTX14 1IR

AtTX14 Full AtTX14 2IR AtTX14 1IR

AtTX14 Full AtTX14 2IR AtTX14 1IR

239 TFKSQKPNFDDEDDDGDSLLKALVAKLVASTTSIVAAYAELQRAHSDAIQAAETVVVDVK 298 $220 \ldots \ldots \ldots \ldots \ldots$

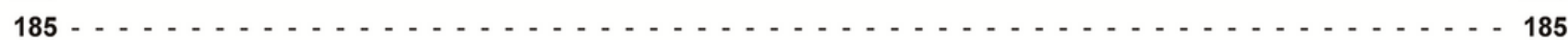

AtTX14 Full AtTX14 2IR AtTX14 1IR

$1 M A$ I ASSSPSSSSNVSVIPTGPQVF I SFRGKELRKGF I SFLVPALKKKN INVF I DEHEVRG 60 $1 M A \mid A S S S P S S S S N V S V I P T G P Q V F$ ISFRGKELRKGF I SFLVPALKKKN INVF I DEHEVRG 60 $1 M A I A S S S P S S S S N V S V I P T G P Q V F$ I SFRGKELRKGF I SFLVPALKKKNINVF I DEHEVRG 60

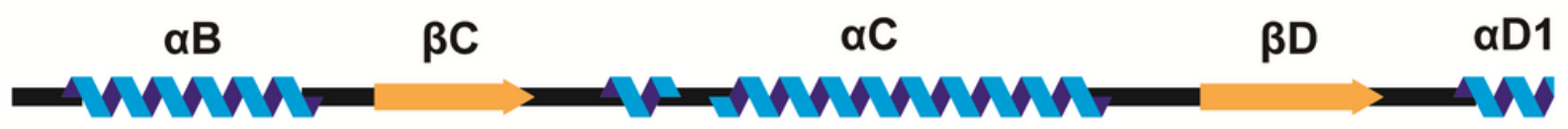

61 KDL I SLFRR I GESKI ALVIFSEGYTESKWCLDELVQ IKKCVDQKK I I A I P IFYKLDPAVV 120 $61 \mathrm{KDL}$ I SLFRR IGESKIALVIFSEGYTESKWCLDELVQIKKCVDQKKI I A I IFYKLDPAVV 120 $61 \mathrm{KDL}$ I SLFRR IGESKIALVIFSEGYTESKWCLDELVQIKKCVDQKKI I A I I FYKLDPAVV 120

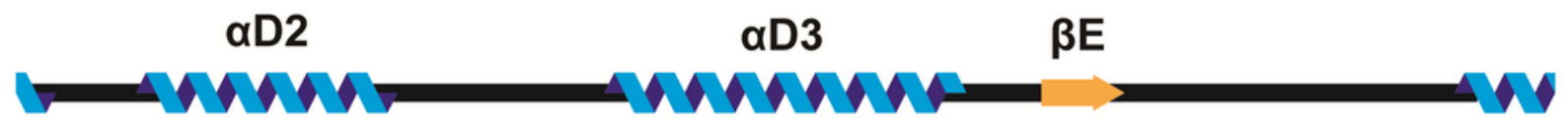

120 KGLKGKFGDKFRDL I ERYHHEPERYQKWTEALTSVSRTFAL CLPEHSDKSEKDF - - IRS I 178 120 KGL KGKFGDKFRDL I ERYHHEPERYQKWTEALTSVSRTFALCLPEHSDKSEKDF - - IRS I 178 120 KGLKGKFGDKFRDL I ERYHHEPERYQKWTEALTSVSRTFALCLPEHRLRFFNHKNCLFLV 180

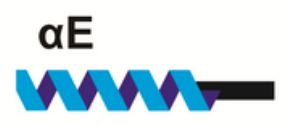

179 I KEVKKALSN I SRERNGDREE I DDCFVVSERKLTT DMYDTPEVSTSTMRKVSSNNGVGVG 238 179 I KEVKKAL SN I SRERNGDREE I DDCF VVSERKL T T DMYDTPE . . . . . . . . . . . 220

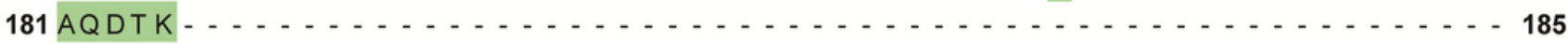

299 TL SEL I RSSNGGGGGSGSGSGSSLENQPRRSKVRKQVWAEVLGISSDSTI ILECI - - - - 353

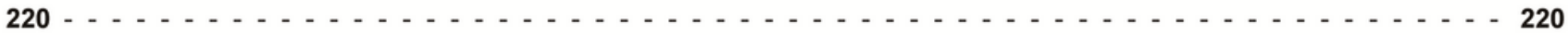

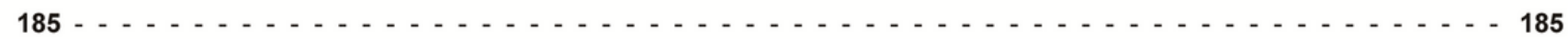

Figure 2

AtTX14 1IR with the retained first intron lacks aE helix of TIR domain. Sequence alignment and predicted secondary structure of the three AtTX14 proteins For secondary structures of the TIR domain, $\beta$-strands and a-helices are indicated by arrows and spirals, respectively, while loops are indicated by bold lines. Amino acid sequences encoded by the retained first and second introns are shaded. 
a
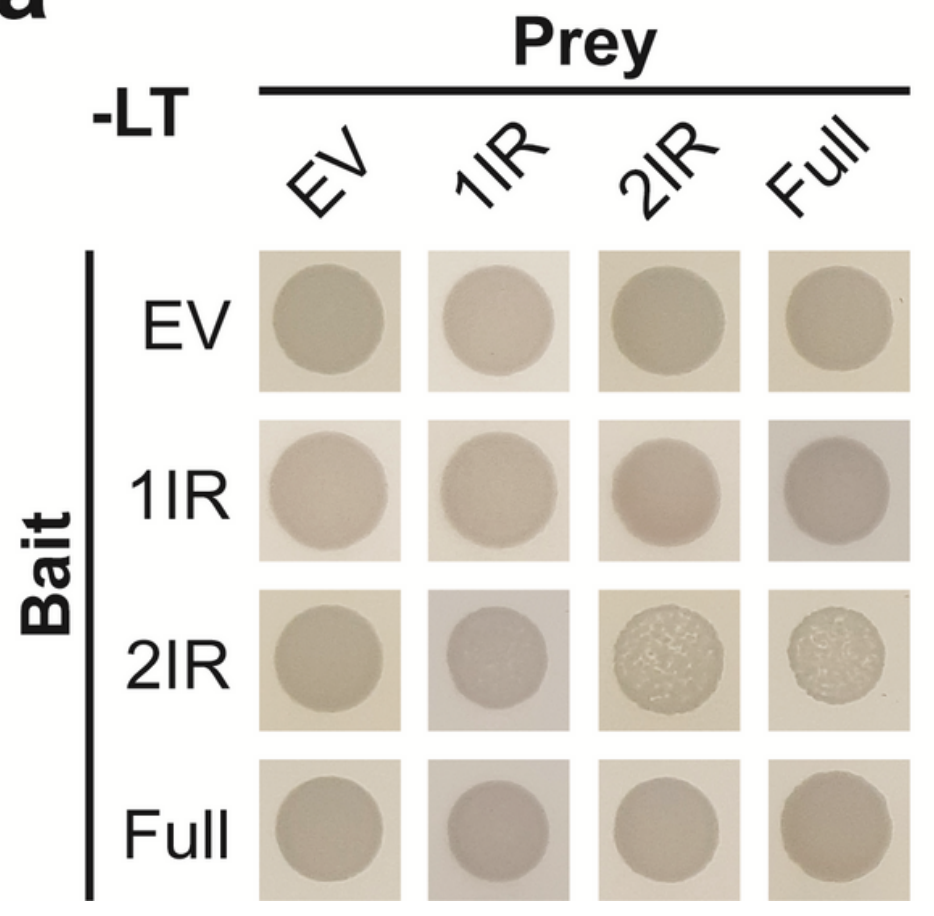

b

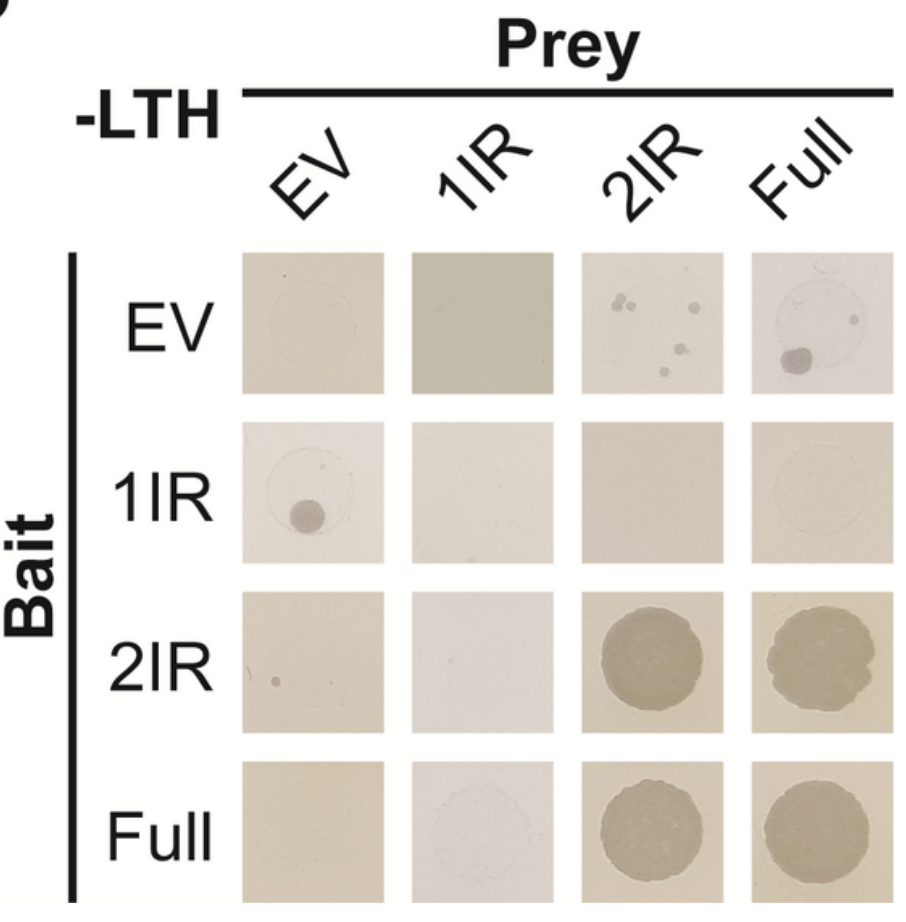

Figure 3

aE helix of TIR domain is important for homo- or heterodimer formation of AtTX14 proteins. Growth of yeast cells expressing different AtTX14 splicing products fused to the GAL4 DNA binding domain (GAL4 $B D$ ) as bait or GAL4 activation domain (GAL4 AD) as prey. Y2H results on media without leucine and tryptophan (-LT) (A) and selective media without leucine, tryptophan, and histidine (-LTH) (B) are shown. Yeast indicated with EV (empty vector) for bait or prey carry empty bait or prey vector without the AtTX14coding sequence. 
a

WT

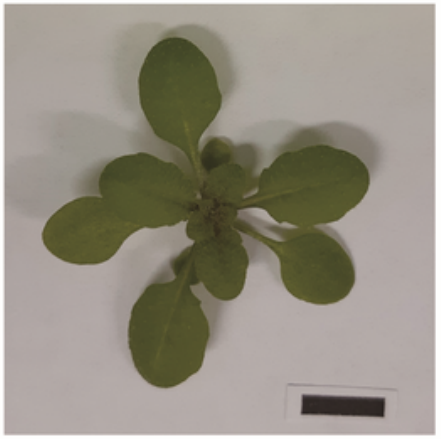

2IR \#4

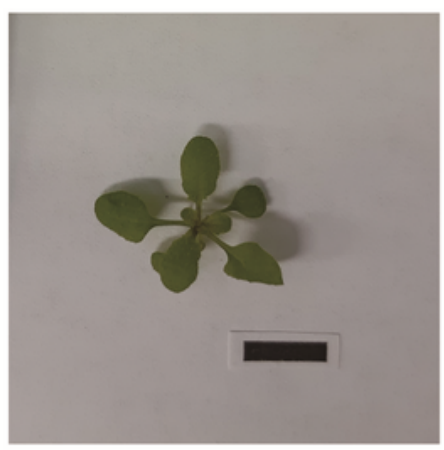

gAtTX14 \#18

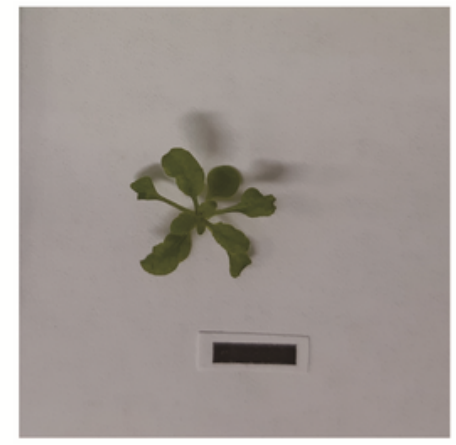

2IR \#5

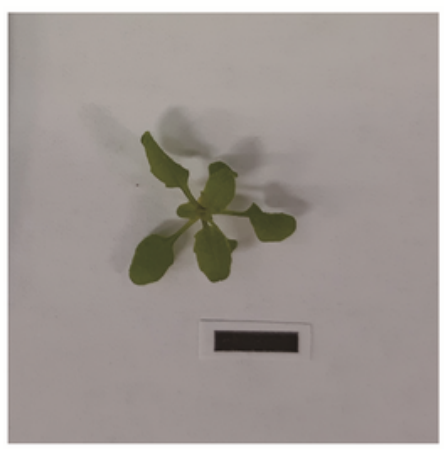

1IR \#11

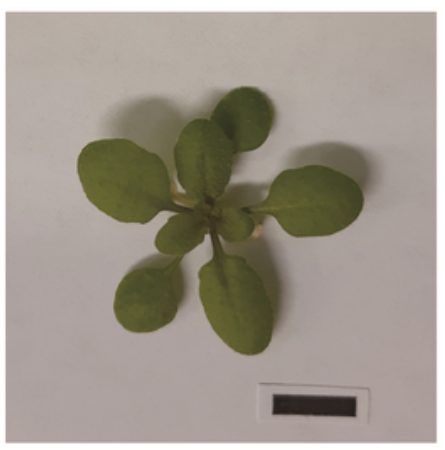

Full \#9

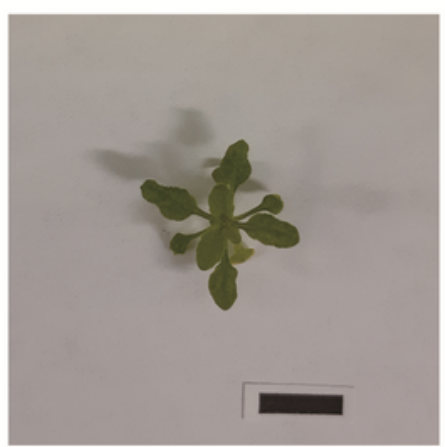

1IR \#18

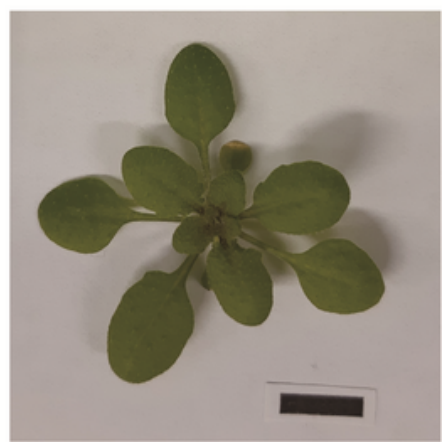

Full \#16

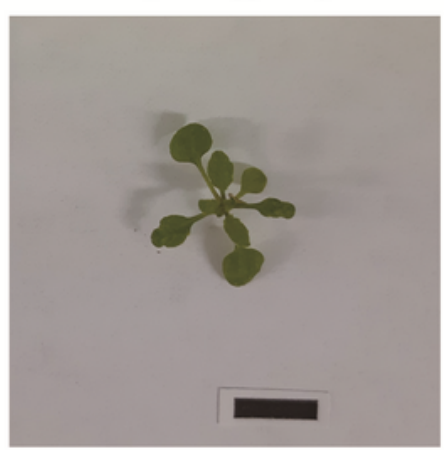

b
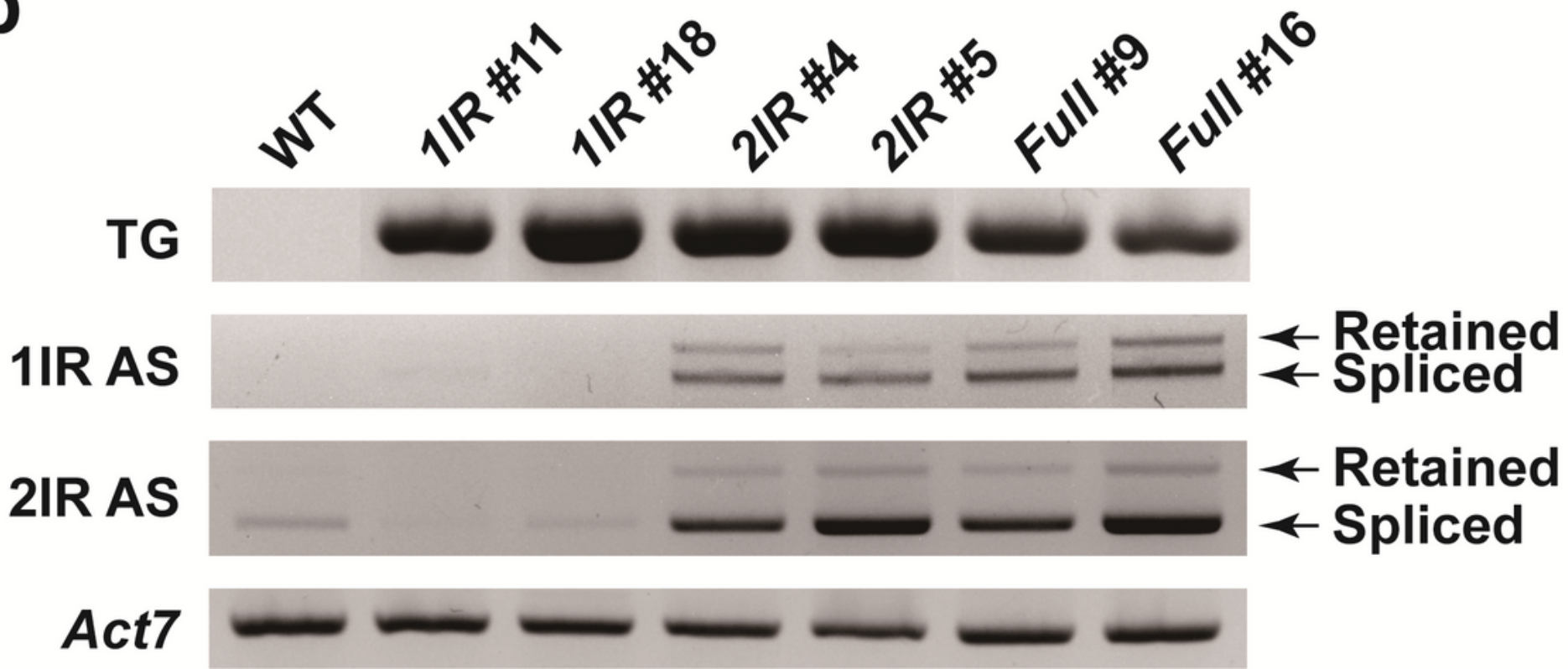

Figure 4

Transgenic overexpression of AtTX14 2IR or Full induces dwarf phenotypes. (A) Phenotypes of WT and transgenic plants, grown for $18 \mathrm{~d}$ at $22^{\circ} \mathrm{C}$ under long-day conditions. gAtTX14 \#18 plant has a transgene with an AtTX14 genomic region under the control of a CaMV 35S promoter. 1IR, 2IR, and Full transgenic plants show phenotypes of two independent transgenic lines overexpressing corresponding coding sequences are shown. Scale bar $=1 \mathrm{~cm}$. (B) Semi-quantitative RT-PCR results showing the expression 
levels of AtTX14 transcripts produced from endogenous or transgenic copies of AtTX14. TG: PCR products amplified from cDNA of AtTX14 transgene. 1IR AS: PCR products amplified from cDNA of endogenous AtTX14, with (Retained) or without (Spliced) the first intron. 2IR AS: PCR products amplified from cDNA of endogenous AtTX14, with (Retained) or without (Spliced) the second intron. Actin7 (Act7) was used as a normalization control. Information on primers used here is found in Table S1 and Fig. S5.

a

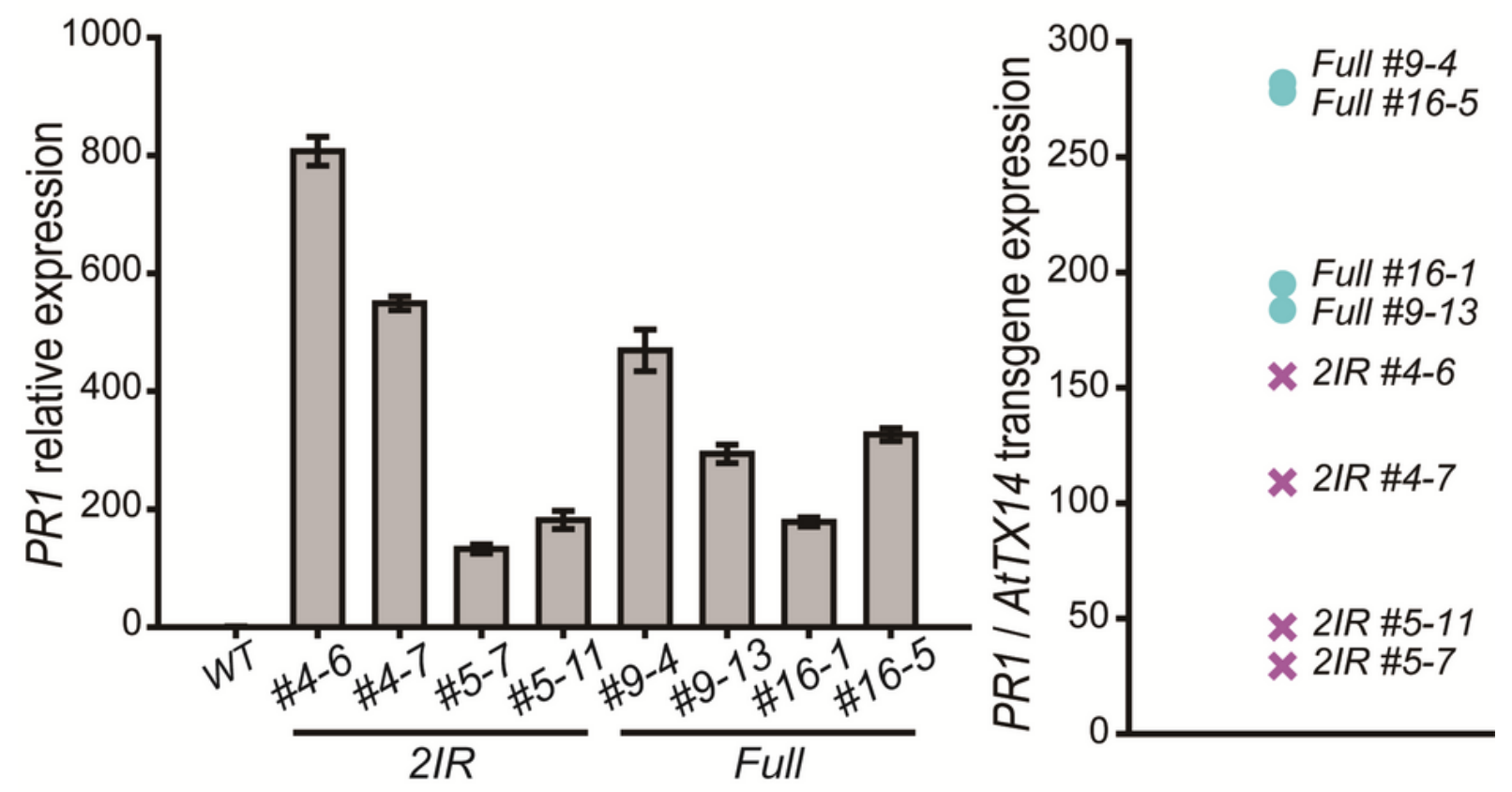

C

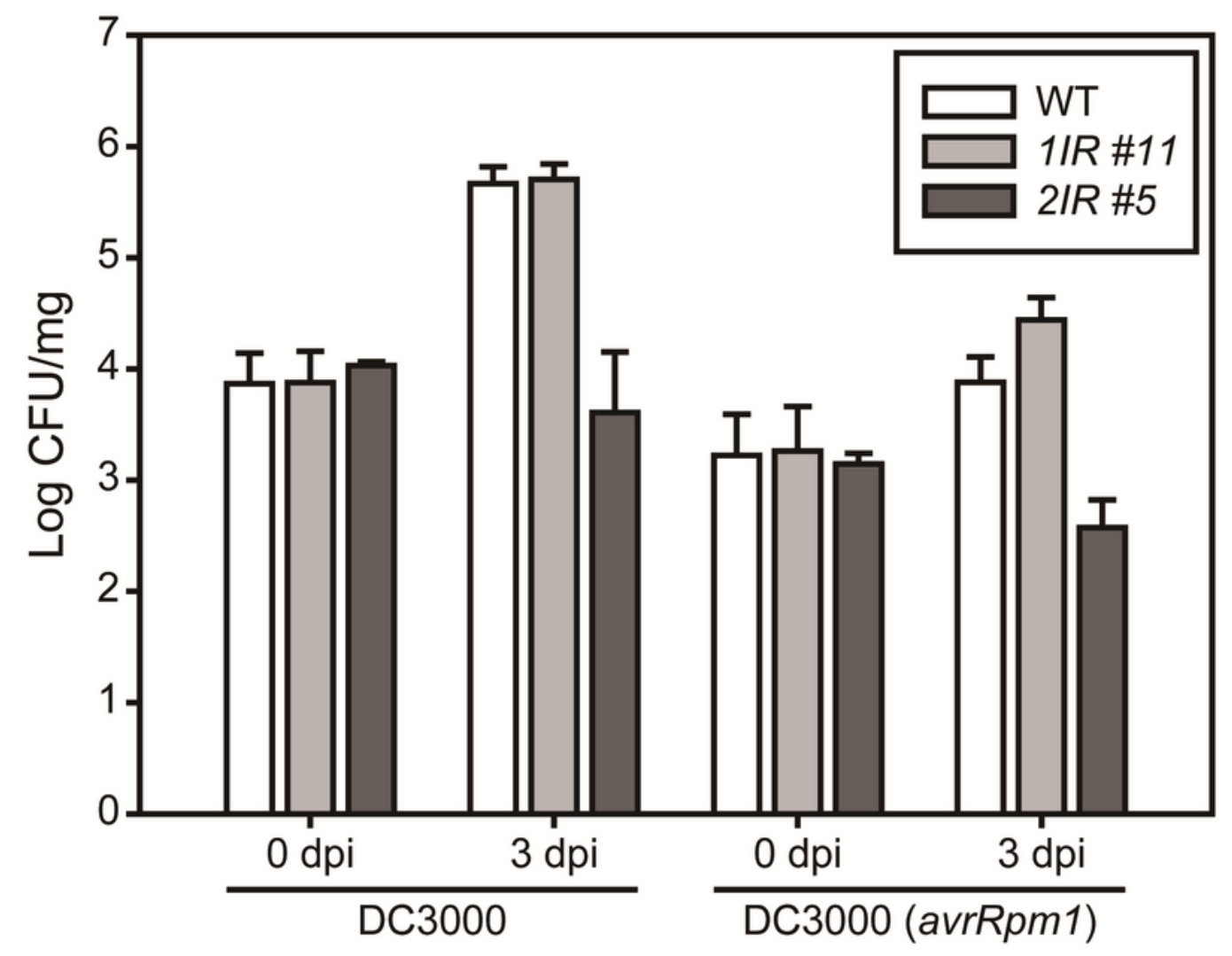

Figure 5 
PR1 expression is induced in AtTX14 2IR and Full transgenic plants. (A) Quantitative RT-PCR analyses showing expression levels of PR1. (B) Ratios of expression levels of PR1 to those of transgenes. The ratios were calculated based on transgene expression levels (Fig. 4B) and PR1 (Fig. 5A) after normalizing with Act7. Circles and crosses show the calculated ratios for AtTX14 Full and 2IR transgenic plants, respectively. (C) Representative results showing growth of DC3000 and DC3000 (AvrRpm1) in WT, AtTX14 1IR, and AtTX14 2IR transgenic plants at 0 and 3 d post-infection (dpi). DC3000 and DC3000 (AvrRpm1) are Pst without the AvrRpm1 effector and with AvrRpm1 effector, respectively, which were used for infiltration. CFU: colony-forming unit. Error bars indicate standard deviations.

a

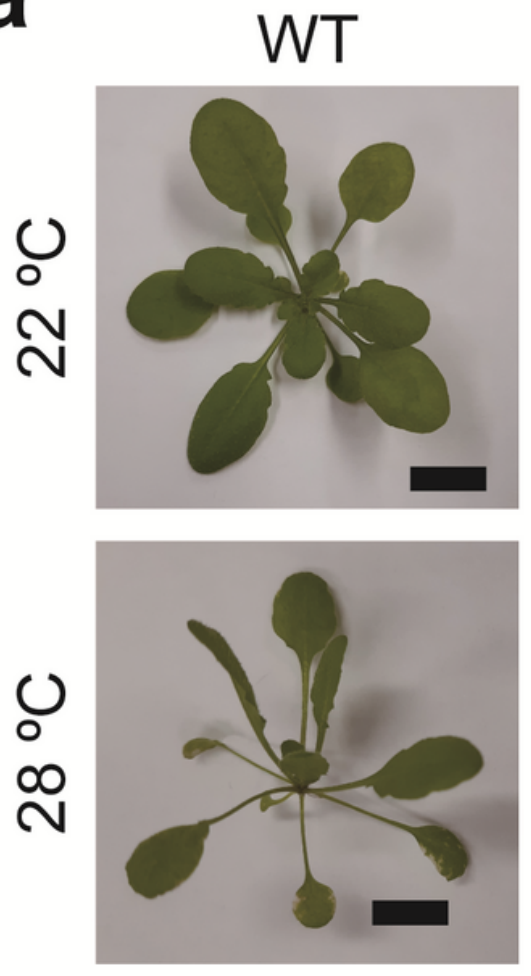

2IR \#4
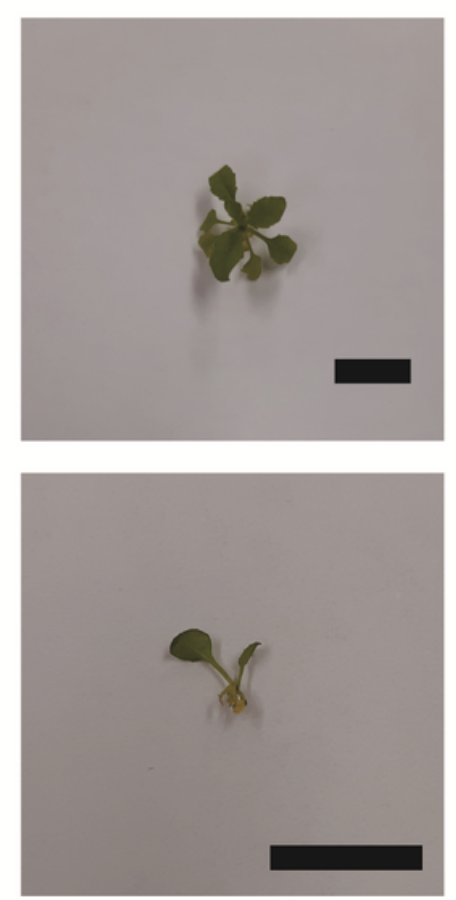

b

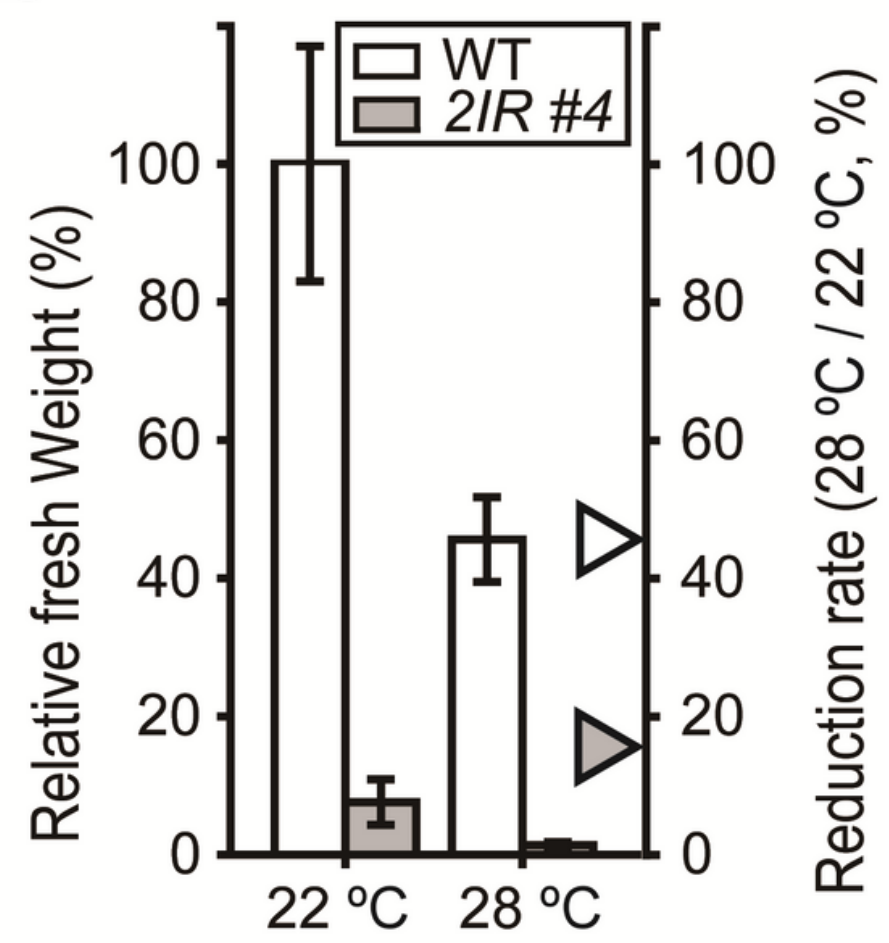

\section{Figure 6}

High temperature reinforces the dwarf phenotypes of AtTX14 2IR transgenic plant. (A) Phenotypes of WT and 2IR \#4. Scale bar $=1 \mathrm{~cm}$. (B) Relative fresh weight of WT and 2IR \#4, compared with the fresh weight of WT. Triangles show reduction rates between 28 and $22^{\circ} \mathrm{C}$. Plants were grown for $18 \mathrm{~d}$ at $22^{\circ} \mathrm{C}$ or $14 \mathrm{~d}$ at $28^{\circ} \mathrm{C}$ until plants start bolting under long-day conditions. 

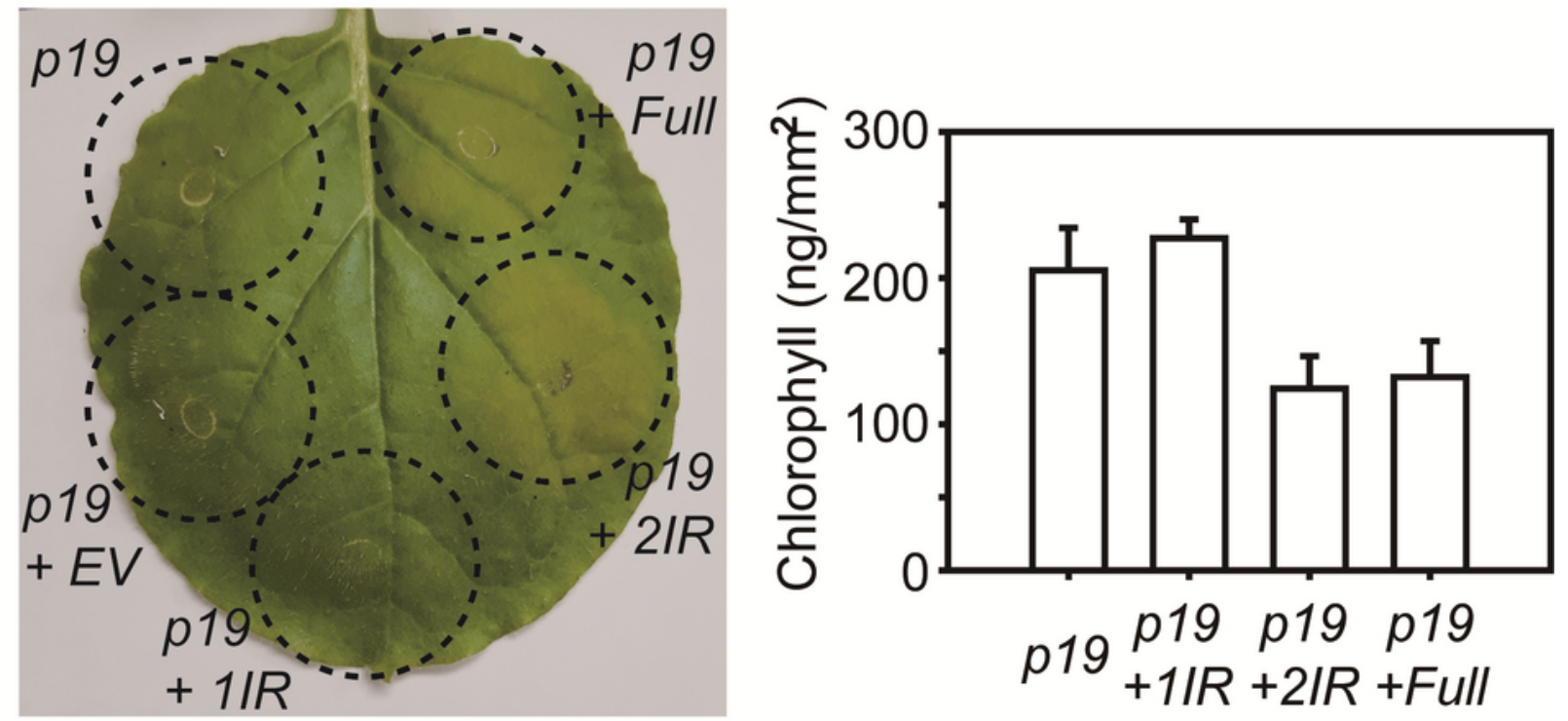

0

Figure 7

Expression of AtTX14 2IR or Full induces HR in tobacco. (A) Pictures of tobacco leaves taken $10 \mathrm{~d}$ after Agrobacterium infiltration. The regions circled with dashed lines were infiltrated with a single or a mix of Agrobacterium for plant expression of indicated proteins. p19: RNA silencing suppressor. No protein: No AtTX14-encoded protein. 1IR: AtTX14 1IR. 2IR: AtTX14 2IR. Full: AtTX14 Full. Note that the same total amounts of Agrobacterium cells were used for each infiltration, except "p19". (B) Chlorophyll content in 
Agrobacterium-infiltrated tobacco leaf segments. P19+1IR, P19+2IR, or P19+Full shows chlorophyll content measured in leaf segments transiently expressing AtTX14 1IR, 2IR, or Full, along with the p19 RNA silencing suppressor. Error bars in the graph show standard errors.

\section{Supplementary Files}

This is a list of supplementary files associated with this preprint. Click to download.

- FigureS1.TIR.tif

- FigureS2.DUF641.tif

- FigureS3.Y2Hwestern.tif

- FigureS4.balFullRT210301.tif

- FigureS5.RTPCRPrimerPosition210301.tif

- Tables1.docx 